\title{
Factors Related to Affective Occupational Commitment among Japanese Nurses
}

\author{
Miho Satoh1, Ikue Watanabe'2, Kyoko Asakura³ \\ ${ }^{1}$ Tokyo Healthcare University, Tokyo, Japan \\ ${ }^{2}$ Tohoku Fukushi University, Sendai, Japan \\ ${ }^{3}$ Graduate School of Medicine, Tohoku University, Sendai, Japan \\ Email: mihos-tky@umin.ac.jp
}

How to cite this paper: Satoh, M., Watanabe, I. and Asakura, K. (2017) Factors Related to Affective Occupational Commitment among Japanese Nurses. Open Journal of Nursing, 7, 449-462.

https://doi.org/10.4236/ojn.2017.73035

Received: March 3, 2017

Accepted: March 28, 2017

Published: March 31, 2017

Copyright $\odot 2017$ by authors and Scientific Research Publishing Inc. This work is licensed under the Creative Commons Attribution International License (CC BY 4.0).

http://creativecommons.org/licenses/by/4.0/

\begin{abstract}
We identified the factors related to affective occupational commitment among nurses in Japan by conducting a cross-sectional survey in 12 hospitals in the Tohoku and Kanto districts of Japan in 2013. Of the 4046 nurses in these hospitals, 1330 completed the self-report questionnaire (valid response rate: 32.9\%). High job satisfaction, high professional autonomy, having a scholarship loan, and being married were strongly related to affective occupational commitment. Conversely, having a high effort-reward imbalance and fewer overtime work hours indicated a low level of such commitment. The findings suggest that professional autonomy and job satisfaction are key factors for developing affective occupational commitment. Programs that promote professional autonomy and make people feel more appreciated for their work should be created to improve such commitment, and it would be important to provide adequate organizational resources to increase job satisfaction and reduce effort-reward imbalance. The fact that longer working hours are related to affective occupational commitment suggests that excessive emotional commitment to one's occupation can lead to overtime work. Therefore, nurse managers should consider the staff's working situations more thoroughly.
\end{abstract}

\section{Keywords}

Affective Occupational Commitment, Psychosocial Work Environment, Nurses, Japan

\section{Introduction}

Occupational commitment is defined as "a psychological link between a person and his or her occupation that is based on an affective reaction to that occupation" [1]. Professionals tend to commit to their occupation rather than the or- 
ganization to which they belong, and nursing professionals are no exception [1] [2]. Researchers have mainly examined occupational commitment among teachers, and have identified a number of related factors, including work stress [3], job satisfaction [4], and psychological well-being [5]. As for other occupations, occupational commitment is considered to have an important impact on creativity [6], knowledge-sharing among employees [7], and productive behavior [8]. These works have shown that occupational commitment affects not only occupational factors or employee's own well-being, but also organizational outcomes, such as worker retention and sustained productivity within the organization. As a result, interest in occupational commitment has been increasing in recent years.

In nursing research, occupational commitment has been of considerable interest in recent years. Studies among nurses have suggested that occupational commitment has a significant association with job satisfaction [9] [10], job performance [11], psychological well-being [12], and professional turnover [13] [14] [15]. Meyer et al. [16] proposed that occupational commitment was a threecomponent model comprising affective, continuance, and normative occupational commitment. Of these three components, affective occupational commitment has been determined to be the strongest predictor of occupational behavior.

Affective occupational commitment refers to the emotional commitment one has to an occupation [1] [16]. Affective occupational commitment has been mainly examined from the perspective of nurse retention. Several studies have shown that affective occupational commitment is a significant indicator of turnover intention and actual turnover among nurses, both inside and outside Japan [10] [17] [18] [19]. Satoh, Asakura, and Watanabe [20] showed that, of the three components of occupational commitment, affective commitment was the strongest influencing factor of intention to continue nursing. Hospitals are increasingly becoming committed to maintaining adequate staffing of nursing personnel [21] [22], and an effective way of improving nurse retention is to enhance their affective occupational commitment.

Although many researchers have explored the contribution of affective occupational commitment to turnover intention among nurses, rather little has been done to clarify the factors promoting affective occupational commitment [20]. While the determinants of organizational commitment have been discussed, there is still a relative paucity of research comprehensively exploring the determinants of occupational commitment, including the associated demographic factors. Indeed, only two meta-analyses have identified the influential factors of occupational commitment [1] [23], which included job satisfaction, professional autonomy, support from coworkers and supervisors, job involvement, job stress, and income. However, these meta-analyses did not focus strictly on affective occupational commitment and looked at occupations beyond just nurses.

Theoretically, affective occupational commitment is influenced by occupational value congruence, job characteristics, work environments, and individual differences [1] [23] [24] [25]. The aim of the current study was to determine the specific factors related to affective occupational commitment among nurses in Japan. This would provide suggestions about intervention programs for promoting 
affective occupational commitment, which in turn could help in preventing nurse turnover and improving intention to stay in the profession.

\section{Methods}

\subsection{Research Design and Participants}

This study used a cross-sectional design and employed the data collected in a previous study by Satoh et al. [20]. Twelve hospitals in the Tohoku and Kanto districts of Japan, all of which had more than 300 beds and a 1:7 nurse-to-patient ratio, agreed to participate. Data were collected from September to October 2013 using a self-report questionnaire.

The sample size for this study was determined using an effect size of 0.2 , statistical power level of 0.8 , and alpha level of less than 0.05 [1] [16] [23]. The estimated number of participants was 1200 participants; thus, 4030 nurses were needed for the current study assuming a response rate of $30 \%$.

Then, we distributed the questionnaire to the 4046 nurses working in the nursing departments of these twelve hospitals. Of these, 1531 nurses (response rate: $37.8 \%)$ returned the questionnaire by mail. We analyzed the data provided by 1330 nurses (valid response rate: $32.9 \%$ ).

\subsection{Measures}

\subsubsection{Affective Occupational Commitment}

We used the Japanese version of the Occupational Commitment Scale [9], originally developed by Meyer et al. [16]. It comprises 6 items, which respondents rate on a scale from 1 (strongly disagree) to 5 (strongly agree). The scores are summed, with higher scores indicating higher levels of commitment.

\subsubsection{Effort-Reward Imbalance (ERI)}

The Japanese short version of the Effort-Reward Imbalance Questionnaire (ERIQ), originally developed by Siegrist and colleagues [26], was used to assess stressful conditions at work. The Japanese short version of the ERI-Q has high validity and reliability [27]. The model on which the ERI-Q is based was developed in the medical sociology field to clarify the effects of efforts and rewards at work [28]. Marmot et al. [28] reported that the ERI model is suitable for explaining stress in service occupations and professions, and health professionals in particular.

The Japanese version of the ERI-Q has three subscales measuring effort (6 items), reward (11 items), and over-commitment (6 items). Effort refers to job demands, responsibility, and workload, while reward refers to what workers can expect to gain through their labor, including money, esteem, and career opportunities. The items in these two subscales are answered in two steps. First, respondents indicate whether each item is a source of stress for them by choosing one of two options: agree or disagree. Those who answer agree are then asked to rate the degree of distress by selecting one of four options ranging from 1 (not at all distressed) to 4 (very distressed). The scores on each scale are then summed, with higher scores indicating that more effort is given and that workers are ex- 
periencing distress (effort) or the greater the rewards that workers obtain.

Over-commitment is a personal factor referring to an individual's use of an exhausting work-related coping style [29] [30]. Respondents rate each item on a scale from 1 (strongly disagree) to 4 (strongly agree), and the scores of all items are summed. A higher total score indicates a greater likelihood of experiencing overcommitment.

\subsubsection{Professional Autonomy}

This was assessed using 7items from the professional autonomy scale developed by Asakura et al. [31]; it has established validity and reliability. The scale evaluates nurses' perceived professional autonomy. The respondents rate the items on a scale from 1 (strongly disagree) to 5 (strongly agree), after which the scores are summed. Higher scores indicate greater professional autonomy.

\subsubsection{Job Satisfaction}

Job satisfaction was assessed using the general job satisfaction scale, a subscale of the Japanese version of the Job Satisfaction Scale [32], originally developed by McLean [33]. The scale comprises 4 items evaluating the degree of overall satisfaction with various working conditions. Respondents rate each item on a scale from 1 (strongly disagree) to 5 (strongly agree), after which the scores are summed. Higher total scores indicate greater job satisfaction.

\subsubsection{Personal and Occupational Characteristics}

We assessed the following demographic and occupational characteristics of respondents: gender, age, marital status, child status, living with persons requiring care, education, number of overtime hours per month, employed status, position, years of nursing experience, own income/household income, and scholarship system.

\subsubsection{Organizational Characteristics}

The number of beds at this hospital, number of nurses in staff at the hospital, and hospital location were assessed.

\subsection{Statistical Analyses}

Descriptive statistics (frequencies, means, and standard deviations) for participants' personal and occupational characteristics were calculated, and Cronbach's a values were calculated for the affective occupational commitment, job satisfaction, ERI, and professional autonomy measures. We used t-tests and one-way analyses of variance (ANOVAs) to compare the variable means. Pearson's correlation coefficients were calculated between affective occupational commitment and the other continuous variables. Furthermore, logistic regression analysis was performed to identify the individual factors associated with affective occupational commitment; in this analysis, affective occupational commitment was dichotomized into high and low using the median split. Personal and employment demographic variables, organizational characteristics, job satisfaction, ERI ratio, over-commitment and professional autonomy were used for independent va- 
riables.

SPSS Statistics 22.0 for Mac [34] was used for the data analysis. Statistical significance was set at $p<0.05$ (two-tailed).

\subsection{Ethical Considerations}

Approval for this study was obtained from the ethics committee of the authors' institution. We requested the cooperation of all of the hospitals' nursing service directors orally and in writing. Participants were informed of the voluntary nature of this study and assured of their right to refuse to participate or withdraw at any time, and of the confidentiality of the data. Participants agreed to take part in the study by completing and returning the questionnaire.

\section{Results}

\subsection{Sample Characteristics}

The sample characteristics are presented in Table 1 . The majority of the sample was female (95.4\%), worked at hospitals in the Tohoku district (62.9\%), and worked at hospitals with 500 - 699 beds (71.0\%). Furthermore, 37.3\% worked at hospitals with more than 700 nursing staff. Respondents' mean age was 37.61 $(S D=10.29)$ and their mean years of clinical experience was $15.52(S D=10.28)$.

\subsection{Affective Occupational Commitment and Personal and Occupational Characteristics}

Of the personal and occupational characteristics, marital status $(p<0.001)$, child status $(p<0.001)$, position $(p<0.001)$, employment status $(p<0.05)$, hospital capacity $(0.01<p<0.05)$, and area of hospital location $(p<0.01)$ were significantly related to affective occupational commitment. More specifically, married nurses, nurses who had children, nurses who worked in hospitals with more than 700 beds, and nurses who worked in the Kanto district had significantly higher affective occupational commitment scores (Table 2).

\subsection{Correlations between Affective Occupational Commitment and Independent Variables}

All continuous variables had significant correlations with affective occupational commitment. Positive correlations were found for age $(\mathrm{r}=0.189, p<0.001)$, years of nursing experience $(\mathrm{r}=0.203, p<0.001)$, job satisfaction $(\mathrm{r}=0.339, p<$ $0.001)$, and professional autonomy $(\mathrm{r}=0.308, p<0.001)$, while negative correlations were found for share of household income $(\mathrm{r}=-0.087, p<0.01)$, ERI $(\mathrm{r}=$ $-0.260, p<0.001)$, and over-commitment $(\mathrm{r}=-0.160, p<0.001)$ (Table 3$)$.

\subsection{Logistic Regression of Affective Occupational Commitment}

The results of the logistic regression analysis for affective occupational commitment are shown in Table 4. Married nurses (odds ratio [OR] 1.54, 95\% confidence interval [CI] 1.04 - 2.28), nurses who had obtained a scholarship (OR 1.34, $95 \%$ CI 1.04 - 1.74), nurses who worked more than 20 hours of overtime work 
Table 1. Sample characteristics.

\begin{tabular}{|c|c|c|c|}
\hline & & $\mathrm{N}$ & $\%^{\dagger}$ \\
\hline \multirow[t]{2}{*}{ Gender } & Female & 1269 & 95.4 \\
\hline & Male & 60 & 4.5 \\
\hline Age & Mean \pm SD & \multicolumn{2}{|c|}{$37.61 \pm 10.29$} \\
\hline Years of nursing experience & Mean \pm SD & \multicolumn{2}{|c|}{$15.52 \pm 10.28$} \\
\hline \multirow[t]{2}{*}{ Marital status } & Married & 700 & 52.6 \\
\hline & Single & 629 & 47.3 \\
\hline \multirow[t]{2}{*}{ Child status } & Have a child & 636 & 47.8 \\
\hline & Do not have a child & 693 & 52.1 \\
\hline \multirow[t]{2}{*}{ Living with persons requiring care } & Yes & 208 & 15.6 \\
\hline & No & 1115 & 83.8 \\
\hline Share of household income & Mean \pm SD & \multicolumn{2}{|c|}{$64.51 \pm 2.80$} \\
\hline \multirow[t]{2}{*}{ Education } & $\begin{array}{l}\text { Community college or } \\
\text { vocational school }\end{array}$ & 1108 & 83.3 \\
\hline & University graduate or higher & 196 & 14.7 \\
\hline \multirow[t]{2}{*}{ Employment status } & Permanent & 1263 & 95.0 \\
\hline & Temporary & 66 & 5.0 \\
\hline \multirow[t]{2}{*}{ Position } & Managerial position & 153 & 11.5 \\
\hline & Staff nurse & 1168 & 87.8 \\
\hline \multirow[t]{2}{*}{ Scholarship system } & Used & 604 & 45.4 \\
\hline & Not used & 726 & 54.6 \\
\hline \multirow[t]{2}{*}{ Hospital location } & Kanto district & 498 & 37.4 \\
\hline & Tohoku district & 831 & 62.5 \\
\hline \multirow[t]{3}{*}{ Number of overtime hours per month } & $<5$ & 211 & 15.9 \\
\hline & $5-20$ & 688 & 51.7 \\
\hline & $\geq 20$ & 419 & 31.5 \\
\hline \multirow[t]{3}{*}{ Number of beds at hospital } & $<500$ & 226 & 17.0 \\
\hline & $500-700$ & 944 & 71.0 \\
\hline & $\geq 700$ & 159 & 12.0 \\
\hline \multirow[t]{3}{*}{ Number of nursing staff members at hospital } & $<500$ & 309 & 23.3 \\
\hline & $500-700$ & 524 & 39.4 \\
\hline & $\geq 700$ & 496 & 37.3 \\
\hline
\end{tabular}

${ }^{\dagger}$ Some percentages do not equal $100 \%$ due to missing data.

Table 2. Comparison of mean scores.

\begin{tabular}{lllll}
\hline & & Mean & SD & $p$ \\
\hline Gender & & & & \\
& Female & 21.22 & 3.89 & \\
& Male & 20.27 & 3.52 & \\
\hline
\end{tabular}




\section{Continued}

Marital status

$$
\begin{aligned}
& \text { Married } \\
& \text { Single }
\end{aligned}
$$

20.49

3.77

Child status

$$
\begin{aligned}
& \text { Have a child } \\
& \text { Do not have a child }
\end{aligned}
$$

3.77

3.87

Living with persons requiring care

$$
\text { Yes }
$$$$
\text { No }
$$

Education
21.42

21.13

21.24

Employment status

$$
\begin{aligned}
& \text { Permanent } \\
& \text { Temporary }
\end{aligned}
$$

$$
3.86
$$

Position

$$
\begin{aligned}
& \text { Managerial position } \\
& \text { Staff nurse }
\end{aligned}
$$

Scholarship system

$$
\begin{aligned}
& \text { Used } \\
& \text { Not used }
\end{aligned}
$$$$
21.27
$$$$
4.09
$$

21.09 3.68

Hospital location

$$
\begin{aligned}
& \text { Kanto district } \\
& \text { Tohoku district }
\end{aligned}
$$

Number of overtime hours per month

$$
\begin{aligned}
& <5 \\
& 5-20 \\
& \geq 20
\end{aligned}
$$

Number of beds at hospital

$$
\begin{aligned}
& <500^{\mathrm{a}} \\
& 500-700^{\mathrm{b}} \\
& \geq 700^{\mathrm{c}}
\end{aligned}
$$

Number of nursing staff members at hospital
$<500$
21.36
20.84
3.91
$500-700$
$21.40 \quad 3.92$

$\begin{array}{ll}21.36 & 3.70 \\ 20.84 & 3.91 \\ 21.40 & 3.92\end{array}$

${ }^{* * *} p<0.001,{ }^{* *} p<0.01,{ }^{*} p<0.05$.

$\begin{array}{ll}21.30 & 3.58 \\ 21.06 & 3.80 \\ 21.29 & 4.13\end{array}$

$21.16 \quad 3.93 \quad a-c^{*}$

$21.00 \quad 3.85 \quad b-c^{* *}$

$22.22 \quad 3.76$ 
Table 3. Correlation Coefficients between Variables

\begin{tabular}{lcccccc}
\hline & Mean & SD & Range & Cronbach's alpha Correlation & $p$ \\
\hline Affective occupational commitment & 21.17 & 3.87 & $6-30$ & 0.837 & - & \\
Age & 37.61 & 10.29 & $2-65$ & - & 0.189 & $* * *$ \\
Years of nursing experience & 15.52 & 10.28 & $0-48$ & - & 0.203 & $* * *$ \\
Share of household income & 64.51 & 2.80 & $0-10$ & - & -0.087 & $* *$ \\
ERI (effort-reward imbalance) & 0.97 & 0.39 & $0.20-3.95$ & - & -0.260 & $* * *$ \\
Over-commitment & 15.48 & 3.36 & $6-24$ & 0.799 & -0.160 & $* * *$ \\
Professional autonomy & 24.97 & 4.10 & $7-35$ & 0.821 & 0.308 & $* * *$ \\
Job satisfaction & 11.14 & 3.56 & $4-20$ & 0.870 & 0.339 & $* * *$ \\
\hline
\end{tabular}

${ }^{* *} p<0.001,{ }^{* *} p<0.01$.

Table 4. Logistic regression analysis.

\begin{tabular}{|c|c|c|c|c|}
\hline & \multirow{2}{*}{ Odds ratio } & \multicolumn{2}{|c|}{$95 \% \mathrm{CI}$} & \multirow{2}{*}{$p$} \\
\hline & & Lower & Upper & \\
\hline Gender (Male = ref.) & 1.49 & 0.79 & 2.81 & \\
\hline Child status (Not Having child = ref.) & 0.83 & 0.56 & 1.24 & \\
\hline Marital status (Single $=$ ref.) & 1.54 & 1.04 & 2.28 & * \\
\hline Living with persons requiring care $(\mathrm{No}=$ ref.) & 1.25 & 0.87 & 1.79 & \\
\hline Share of household income & 0.97 & 0.92 & 1.02 & \\
\hline Years of nursing experience & 1.02 & 1.00 & 1.04 & \\
\hline Position (Managerial position = ref.) & 1.33 & 0.84 & 2.08 & \\
\hline Employment status (Temporary = ref.) & 0.81 & 0.42 & 1.56 & \\
\hline \multicolumn{5}{|c|}{ Number of overtime hours per month $(<5$ hours $=$ ref. $)$} \\
\hline $5-20$ hours & 1.43 & 0.97 & 2.11 & \\
\hline$\geq 20$ hours & 2.18 & 1.39 & 3.40 & $* *$ \\
\hline Scholarship loan (No = ref.) & 1.34 & 1.04 & 1.74 & * \\
\hline Hospital location (Tohoku district $=0$ ) & 1.37 & 0.92 & 2.05 & \\
\hline \multicolumn{5}{|l|}{ Number of beds at hospital ( $\geq 700=$ ref.) } \\
\hline$<500$ & 0.97 & 0.56 & 1.69 & \\
\hline $500-700$ & 0.64 & 0.37 & 1.12 & \\
\hline \multicolumn{5}{|c|}{ Number of nursing staff members at hospital $(\geq 700=$ ref.) } \\
\hline$<500$ & 0.89 & 0.59 & 1.34 & \\
\hline $500-700$ & 0.89 & 0.64 & 1.24 & \\
\hline Job satisfaction & 1.15 & 1.11 & 1.20 & $* * *$ \\
\hline Effort-reward imbalance & 0.40 & 0.26 & 0.62 & $* * *$ \\
\hline Professional autonomy & 1.12 & 1.08 & 1.16 & $* * *$ \\
\hline Over-commitment & 0.98 & 0.93 & 1.02 & \\
\hline
\end{tabular}

${ }^{* * *} p<0.001,{ }^{* *} p<0.01,{ }^{*} p<0.05$. 
per week ( $\geq 20$ h vs. $<5$ h; OR 2.18, 95\% CI 1.39 - 3.40), nurses with higher job satisfaction (OR 1.15, 95\% CI 1.11 - 1.20) and nurses with higher professional autonomy (OR 1.12, 95\% CI 1.08 - 1.16) all had significantly greater odds of having high affective occupational commitment. Conversely, nurses who had a higher ERI score (OR 0.40, 95\% CI 0.26 - 0.62) had significantly lower odds of having high affective occupational commitment.

\section{Discussion}

The aim of this study was to determine the factors related to affective occupational commitment among Japanese hospital nurses. The results of our study indicate that job satisfaction, professional autonomy, effort-reward imbalance, overtime work hours, receipt of a scholarship, and marital status might be key factors influencing affective occupational commitment.

Affective occupational commitment was found to be positively associated with job satisfaction. The relationship between affective occupational commitment and various work-related attitudes, especially job satisfaction, has been confirmed in numerous international studies. Meyer et al. [16], for instance, showed that affective occupational commitment had a positive correlation with job satisfaction when developing an occupational commitment scale among Canadian nurses. Job satisfaction has also been found to be an antecedent of affective occupational commitment in other previous studies [1] [35]. Affective occupational commitment is believed to improve through satisfying work experiences produced by involvement in the nursing profession [16]. Overall, our results agree with those reported by previous studies. However, it should be noted that there is conflicting evidence regarding the causal relationship between affective occupational commitment and job satisfaction; as such, causal links in both directions are possible. In other words, high job satisfaction among nurses might produce stronger affective occupational commitment; however, it is equally likely that higher affective occupational commitment leads to an improvement in job satisfaction. As these are both important factors for predicting nurses' intention to stay [35], we suggest further examinations of affective occupational commitment or job satisfaction to prevent nurse turnover.

Affective occupational commitment and professional autonomy are crucial factors influencing nurses' work attitudes and outcomes. Numerous studies on nurses have clarified the relationship between affective occupational commitment and work-relevant behavior [10] [16] [18] [19] as well as the relationship between professional autonomy and work-relevant behavior [36] [37]. The emotional connection to one's occupation (i.e., affective occupational commitment) is intimately connected with a profession's work behavior [1] [16]. Furthermore, somebody with strong affective occupational commitment is likely to strongly identify with her/his occupation and the various beliefs and values associated with it [1]. Professional autonomy is regarded as a cognitive aspect related to those beliefs and values [31]. Thus, affective occupational commitment and professional autonomy are theoretically related. Our study adds further empirical 
support for this relationship. This relationship was also found in a meta-analysis of occupational commitment studies [1], but that study did not specifically focus on the link between these two variables among nurses.

Compared to the previous two variables, effort-reward imbalance had a negative association with affective occupational commitment. This result accords with previous research shows that job stress has a negative association with affective occupational commitment [1]. Both physically and psychologically demanding jobs might decrease individuals' emotional attachment to the occupation itself, which in turn could increase intention to leave [15]. Nurse managers should thus assign jobs according to staff members' ability and skill and ensure adequate nurse staffing, when possible. Reducing effort-reward imbalance is thought to be difficult, however, given that nursing is a highly demanding profession. The degree to which nurses are rewarded for their efforts can improve the sense of meaning in and emotional attachment to nursing [38]. As such, it would be important for nurse managers to appreciate their nursing staff and provide adequate rewards, and for nurses to understand that they can obtain rewards that correspond with the amount of effort they put into the job. This can potentially reduce the negative effects derived from extrinsic effort.

In Lee et al's [1] meta-analysis of occupational commitment, extremely low correlations were reported between various demographic variables and affective occupational commitment. Similarly, a study of Japanese newly graduated nurses found no significant relationship among individual characteristics, employment attributes, and affective occupational commitment [17]. On the other hand, clinical experience, age, marital status, level of education, occupational position, and having flexible working hours were all found to be associated with greater occupational commitment [2] [10] [38] [39] [40] [41]. Our finding that nurses who are married have a higher level of affective occupational commitment was the exact opposite of Blau's [2] findings, who proposed that higher affective occupational commitment is associated with a greater likelihood of not being, married [2]. However, people's attitudes towards jobs have changed over the decade since Blau's study, and the number of women who continue to work after marriage has been increasing globally. This is perhaps why our results were inconsistent with Blau's. Additionally, the findings of the current study suggest that those who have strong affective occupational commitment have a greater intention to remain in nursing in that they are willing to juggle their work and family life after marriage-in other words, their high affective occupational commitment makes them less likely to leave their jobs after marriage.

We identified the use of scholarship loans as a factor related to affective occupational commitment. Previous studies have reported that aspiration to progress and be proactive in self-improvement can increase affective occupational commitment [2] [16]. Our study is indirectly congruent with that finding, in that nurses who pursue a scholarship loan are likely to possess such aspirations. Note that we did not find any significant differences in the means of affective occupational commitment by scholarship use status, but the logistic regression analysis 
confirmed the latter as a strong predictor of the former. This suggests that confounding factors might have obscured the association between affective occupational commitment and scholarship use status.

Regarding overtime work hours, nurses who worked more than 20 hours of overtime work per week tended to demonstrate higher affective occupational commitment. No other study that examined this relationship found the same. Our findings suggest that nurses with high affective occupational commitment are more likely to become absorbed in their jobs, and thus will work longer hours. Excessive commitment to work is considered to facilitate longer working hours. However, because overwork can have an adverse effect on physical and psychological health [30] [42], nurse managers should manage work hours according to nursing staffs workload or work conditions. Furthermore, higher affective occupational commitment might be a stress reaction to effort-reward imbalance [26] [43]. Thus, nurse managers should pay attention to staff showing such tendencies.

Although few studies have reported on the association between affective occupational commitment and demographic variables, this study showed different findings from those conducted previously. It is important that the demographic characteristics related to affective occupational commitment are understood in order to devise efforts to improve such commitment. Further research is needed to explore the individual differences and other demographic variables related to affective occupational commitment.

\section{Limitations}

First, because respondents were all nurses working in the Tohoku and Kanto districts of Japan, and thus may not be representative of Japan, caution must be taken when generalizing the results. The low response rate might also have influenced the generalizability of the findings. Another survey using a national sample of Japanese nurses would be useful. Second, we could not establish causal relationships with certainty in this cross-sectional study; longitudinal studies would be needed to investigate causality in the future. Finally, to examine the topic more comprehensively, researchers should include other psychosocial environmental variables that might relate to affective occupational commitment.

\section{Conclusion}

This study revealed that professional autonomy and job satisfaction could improve affective occupational commitment. Antithetically, effort-reward imbalance is associated with lower affective occupational commitment among Japanese nurses. To improve affective occupational commitment, intervention programs targeting relevant personal resources (i.e., skill, knowledge, and resilience) should be developed. Additionally, organizational resources, such as adequate staffing, easy access to support, and useful information must be provided to increase job satisfaction and reduce effort-reward imbalance. More than 20 hours of overtime work per week was also positively related to high affective occupa- 
tional commitment. Nurses who work longer hours might have an excessive emotional commitment to their occupation. Therefore, nurse manager should take staff's working situations into consideration.

\section{Acknowledgements}

The authors would like to express the deepest appreciation to all nurses who participated in this study, as well as the nurse managers of the 12 cooperating hospitals. This study was supported by a Grant-in-Aid for Scientific Research (C) (No. 23593122) and the Health Care Science Institute.

\section{References}

[1] Lee, K., Carswell, J.J. and Allen, N.J. (2000) A Meta-Analytic Review of Occupational Commitment: Relations with Person- and Work-Related Variables. Journal of Applied Psychology, 85, 799-811. https://doi.org/10.1037/0021-9010.85.5.799

[2] Blau, G. (2003) Testing for a Four-Dimensional Structure of Occupational Commitment. Journal of Occupational and Organizational Psychology, 76, 469-488. https://doi.org/10.1348/096317903322591596

[3] Klassen, R.M. and Chiu, M.M. (2011) The Occupational Commitment and Intention to Quit of Practicing and Pre-Service Teachers: Influence of Self-Efficacy, Job Stress, and Teaching Context. Contemporary Educational Psychology, 26, 114-129.

[4] Canrinus, E.T., Helms-Lorenz, M., Beijaard, D., Buitink, J. and Hofman, W.H.A. (2012) Self-Efficacy, Job Satisfaction, Motivation and Commitment: Exploring the Relationship between Indicators of Teachers' Professional Identity. European Journal of Psychology of Education, 27, 115-132. https://doi.org/10.1007/s10212-011-0069-2

[5] Morin, A.J.S., Meyer, J.P., McInerney, D.M., Marsh, H.W. and Ganotice, F.A. (2015) Profiles of Dual Commitment to the Occupation and Organization: Relation to Well-Being and Turnover Intention. Asia Pacific Journal of Management, 32 717-744. https://doi.org/10.1007/s10490-015-9411-6

[6] Madjar, N., Greenberg, E. and Chen, Z. (2011) Factors for Radical Creativity, Incremental Creativity, and Routine, Noncreative Performance. Journal of Applied Psychology, 96, 730-743. https://doi.org/10.1037/a0022416

[7] Swart, J., Kinnie, N., van Rossenberg, Y. and Yalabik, Z.Y. (2014) Why Should I My Knowledge? A Multiple Foci of Commitment Perspective. Human Resource Management Journal, 24, 269-289. https://doi.org/10.1111/1748-8583.12037

[8] Becker, T.E., Kernan, M.C., Clark, K.D. and Klein, H.I. (2015) Dual Commitments to Organization and Professions: Different Motivational Pathways to Productivity. Journal of Management. https://doi.org/10.1177/0149206315602532

[9] Satoh, M., Asakura, K., Watanabe, I. and Shimojo, Y. (2015) Reliability and Validity of the Japanese Version of the Occupational Commitment Scale. Journal of Japan Academy of Nursing Science, 35, 63-71. (In Japanese) https://doi.org/10.5630/jans.35.63

[10] Wang, L., Tao, H., Ellenbecker, C.H. and Liu, X. (2012) Job Satisfaction, Occupational Commitment and Intent to Stay among Chinese Nurses: A Cross-Sectional Questionnaire Survey. Journal of Advanced Nursing, 68, 539-549. https://doi.org/10.1111/j.1365-2648.2011.05755.x

[11] Benligiray, S. and Sonmez, H. (2010) Analysis of Demographic and Work Life Variables Which Affect the Occupational Commitment of Nurses. Journal of Management Development, 32, 419-434. https://doi.org/10.1108/02621711311326392 
[12] Sawada, T. (2009) The Relationship of Occupational and Organizational Commitment with Professional Activities and Burnout Tendencies in Nurses. The Japanese Journal of Psychology, 80, 131-137. (In Japanese) https://doi.org/10.4992/jjpsy.80.131

[13] Parry, J. (2008) Intention to Leave the Profession: Antecedents and Role in Nurse Turnover. Journal of Advanced Nursing, 64, 157-167. https://doi.org/10.1111/j.1365-2648.2008.04771.x

[14] Jourdain, G. and Chenevert, D. (2010) Job Demands-Resources, Burnout and Intention to Leave the Nursing Profession: A Questionnaire Survey. International Journal of Nursing Studies, 47, 709-722. https://doi.org/10.1016/j.ijnurstu.2009.11.007

[15] Numminen, O., Leion-Kilpi, H., Isoasho, H. and Meretoja, R. (2016) Newly Graduated Nurses' Occupational Commitment and Its Associations with Professional Competence and Work-Related Factors. Journal of Clinical Nursing, 25, 117-126. https://doi.org/10.1111/jocn.13005

[16] Meyer, J.P., Allen, N.J. and Smith, C.A. (1993) Commitment to Organizations and Occupations: Extension and Test of a Three-Component Conceptualization. Journal of Applied Psychology, 78, 538-551. https://doi.org/10.1037/0021-9010.78.4.538

[17] Azuma, T. and Suzuki, E. (2007) Factors Affecting Occupational Commitment among Novice Nurses in University Hospitals. The Journal of the Japan Academy of Nursing Administrations, 11, 30-40. (In Japanese)

[18] Chang, H.T., Chi, N.W. and Miao, M.C. (2007) Testing the Relationship between Three-Component Organizational/Occupational Commitment and Organizational/Occupational Turnover Intention Using a Non-Recursive Model. Journal of Vocational Behavior, 70, 352-368.

[19] Gambino, K.M. (2010) Motivation for Entry, Occupational Commitment and Intent to Remain: Survey Regarding Registered Nurse Retention. Journal of Advanced Nursing, 66, 2532-2541. https://doi.org/10.1111/j.1365-2648.2010.05426.x

[20] Satoh, M., Watanabe, I. and Asakura, K. (2016) Occupational Commitment and Job Satisfaction Mediate Effort-Reward Imbalance and the Intention to Continue Nursing. Journal of Japan Academy of Nursing Science, 14, 49-60. https://doi.org/10.1111/jjns.12135

[21] Van den Heede, K., Florquin, M., Bruyneel, L., Aiken, L., Diya, L., Lesaffre, E. and Sermeus, W. (2013) Effective Strategies for Nurse Retention in Acute Hospitals: A Mixed Method Study. International Journal of Nursing Studies, 50, 185-194. https://doi.org/10.1016/j.ijnurstu.2011.12.001

[22] Drennan, V.M., Halter, M., Gale, J. and Harris, R. (2016) Retaining Nurses in Metropolitan Areas: Insights from Senior Nurse and Human Resource Managers. Journal of Nursing Management, 24, 1041-1048. https://doi.org/10.1111/jonm.12402

[23] Cooper-Hakim, A. and Viswesvaran, C. (2005) The Construct of Work Commitment: Testing an Integrative Framework. Psychological Bulletin, 131, 241-259. https://doi.org/10.1037/0033-2909.131.2.241

[24] Meyer, J.P. and Allen, N.J. (1991) A Three-Component Conceptualization of Organizational Commitment. Human Resource Management Review, 1, 61-89.

[25] Vandenberghe, C. (2009) Organizational Commitments. In: Klein, H.J., Becker, T.E. and Meyer, J.P., Eds., Commitment in Organizations. Accumulated Wisdom and New Directions (SIOP Organizational Frontiers Series), Routledge, New York, 6995.

[26] Siegrist, J., Starke, D., Chandola, T., Godin, I., Marmot, M., Niedhammer, I. and Peter, R. (2004) The Measurement of Effort-Reward Imbalance at Work: European Comparisons. Social Science \& Medicine, 58, 1483-1499. 
[27] Tsutsumi, A., Ishitake, T., Peter, R., Siegrist, J. and Matoba, T. (2001) The Japanese Version of the Effort-Reward Imbalance Questionnaire: A Study in Dental Technicians. Work \& Stress, 15, 86-96. https://doi.org/10.1080/02678370118173

[28] Marmot, M., Siegrist, J., Theorell, T. and Feeney, A. (1999) Health and the Psychosocial Environment at Work. In: Marmot, M. and Wilkinson, R.G., Eds., Social Determinants of Health, Oxford University Press, Oxford, 105-131.

[29] Preckel, D., Meinel, M., Kudielka, B.M., Hans-Joachim Haug, H.J. and Fischer, J.E. (2007) Effort-Reward-Imbalance, Overcommitment and Self-Reported Health: Is It the Interaction That Matters? Journal of Occupational and Organizational Psychology, 80, 91-107. https://doi.org/10.1348/096317905X80183

[30] Siegrist, J. (1996) Adverse Health Effects of High-Effort/Low-Reward Conditions. Journal of Occupational Health Psychology, 1, 27-41. https://doi.org/10.1037/1076-8998.1.1.27

[31] Asakura, K., Satoh, M. and Watanabe, I. (2016) The Development of the Attitude toward Professional Autonomy Scale for Nurses in Japan. Psychological Reports, 119, 761-782. https://doi.org/10.1177/0033294116665178

[32] Tanaka, M. (1998) A Study on the Factors of Job Satisfaction and Its Scale. Waseda Psychological Reports, 30, 29-36. (In Japanese)

[33] McLean, A.A. (1979) Work Stress. Addison-Wesley, Boston.

[34] IBM Corp. (2013) IBM SPSS Statistics for Windows, Version 22.0. IBM Corp., Armonk, NY.

[35] Van der Heijden, B.I.J.M., Van Dam, K. and Hasselhorn, H.M. (2009) Intention to Leave Nursing: The Importance of Interpersonal Work Context, Work-Home Interference, and Job Satisfaction beyond the Effect of Occupational Commitment. Career Development International, 14, 616-635. https://doi.org/10.1108/13620430911005681

[36] Lin, B.Y., Lin, Y.K., Lin, C.C. and Lin, T.T. (2013) Job Autonomy, Its Predispositions and Its Relation to Work Outcomes in Community Health Centers in Taiwan. Health Promotion International, 28,166-177. https://doi.org/10.1093/heapro/dar091

[37] O’Brien-Pallas, L., Murphy, G.T., Shamian, J., Li, X. and Hayes, L.J. (2010) Impact and Determinants of Nurse Turnover: A Pan-Canadian Study. Journal of Nursing Management, 18, 1073-1086. https://doi.org/10.1111/j.1365-2834.2010.01167.x

[38] Weng, Q. and McElroy, J.C. (2012) Organizational Career Growth, Affective Occupational Commitment and Turnover Intentions. Journal of Vocational Behavior, 80, 256-265.

[39] Omdahl, B. and O’Donnell, C. (1999) Emotional Contagion, Empathic Concern and Communicative Responsiveness as Variables Affecting Nurses' Stress and Occupational Commitment. Journal of Advanced Nursing, 29, 1351-1359. https://doi.org/10.1046/j.1365-2648.1999.01021.x

[40] Nogueras, D.J. (2006) Occupational Commitment, Education, and Experience as a Predictor of Intent to Leave the Nursing Profession. Nursing Economic\$, 24, 86-93.

[41] Drey, N., Gould, D. and Allan, T. (2009) The Relationship between Continuing Professional Education and Commitment to Nursing. Nursing Education Today, 29, 740-745. https://doi.org/10.1016/j.nedt.2009.03.008

[42] Swider, B.W. and Zimmerman, R.D. (2010) Born to Burnout: A Meta-Analytic Path Model of Personality, Job Burnout, and Work Outcomes. Journal of Vocational Behavior, 76, 487-506.

[43] Siegrist, J. (2008) Effort-Reward Imbalance and Health in a Globalized Economy. Scandinavian Journal of Work, Environment \& Health, 34, 163-168. 
Submit or recommend next manuscript to SCIRP and we will provide best service for you:

Accepting pre-submission inquiries through Email, Facebook, LinkedIn, Twitter, etc. A wide selection of journals (inclusive of 9 subjects, more than 200 journals)

Providing 24-hour high-quality service

User-friendly online submission system

Fair and swift peer-review system

Efficient typesetting and proofreading procedure

Display of the result of downloads and visits, as well as the number of cited articles Maximum dissemination of your research work

Submit your manuscript at: http://papersubmission.scirp.org/

Or contact ojn@scirp.org 